\title{
A RESPONSABILIDADE CIVIL DOS ADMINISTRADORES E CONTROLADORESDE INSTITUIÇÕES FINANCEIRAS NOS REGIMES INTERVENTIVOS DO BANCO CENTRAL DO BRASIL
}

\begin{abstract}
Dissertação em Mestrado apresentada Banca Examinadora do Programa de Pós-Graduação em Direito da Faculdade de Direito da Universidade de São Paulo, como exigência parcial para obtenção do título de Mestre em Direito Comercial, sob orientação do Prof. Dr. Marcos Paulo de Almeida Salles.
\end{abstract}

UNIVERSIDADE DE SÃO PAULO

FACULDADE DE DIREITO

São Paulo - SP

2018 
Autorizo a reprodução e divulgação parcial deste trabalho, por qualquer meio convencional ou eletrônico, para fins de estudo e pesquisa, desde que citada a fonte.

\section{Catalogação da Publicação}

Faculdade de Direito da Universidade de São Paulo

AMARO, Anderson de Souza.

A responsabilidade civil dos administradores e controladores de instituições financeiras nos regimes interventivos do Banco Central do Brasil/ Anderson de Souza Amaro; orientador Marcos Paulo de Almeida Salles - São Paulo, 2018.

$141 \mathrm{f}$.

Dissertação (Mestrado) - Universidade de São Paulo, 2018.

I. Responsabilidade Civil. II. Administradores. III. Instituições Financeiras. IV. Regimes Especiais. V. Banco Central do Brasil. 
Nome: AMARO, Anderson de Souza.

Título: A responsabilidade civil dos administradores e controladores de instituições financeiras nos regimes interventivos do Banco Central do Brasil.

Dissertação em Mestrado apresentada Banca Examinadora do Programa de Pós-Graduação em Direito da Faculdade de Direito da Universidade de São Paulo, como exigência parcial para obtenção do título de Mestre em Direito Comercial, sob orientação do Prof. Dr. Marcos Paulo de Almeida Salles.

Aprovado em:

BANCA EXAMINADORA

Prof. (a) Instituição:

Julgamento: Assinatura:

Prof. (a) Instituição:

Julgamento: Assinatura:

Prof. (a) Instituição:

Julgamento: Assinatura: 

À Catarina e seu sorriso 



\section{AGRADECIMENTOS}

Este trabalho - e seu autor - tem algumas dívidas de gratidão que merecem aqui ser destacadas. A primeira delas é, inegavelmente, com a professora Vera Helena de Mello Franco, que originalmente me aprovou no curso de pós-graduação, acreditando na importância e no potencial de discussão acadêmica do tema ora apresentado. Sua pessoa e sua obra estão, sem dúvida, imortalizadas na Academia.

Ao professor Marcos Paulo de Almeida Salles, sempre cortês e atencioso, que tão gentilmente me acolheu como seu orientando, sempre auxiliando com ensinamentos de grande valia.

Agradeço, ainda, aos meus pais, Marise e José Alberto, casal simples e que, apesar de todas as dificuldades, sempre empenharam seus melhores esforços em minha formação, sabedores do valor da educação e do conhecimento. Este momento também é deles.

Por fim, agradeço à minha esposa, Débora, corretora incansável deste trabalho e que me deu a maior alegria que poderia ter na vida, minha pequena Catarina. 

Segue o teu destino, Rega as tuas plantas, Ama as tuas rosas. O resto é a sombra De árvores alheias. (Fernando Pessoa) 



\section{RESUMO}

Se fosse possível resumir em poucas palavras a função do administrador de qualquer sociedade empresária, a descrição de suas tarefas seria a gestão dos fluxos e do patrimônio da empresa administrada, com vistas a entrega dos produtos e serviços, sua permanência no mercado e a geração de lucros. Em suma, o administrador é um dos principais responsáveis pelo sucesso de qualquer empreendimento. Por esse motivo, o estudo da responsabilidade jurídica desse profissional sempre suscitou muito interesse da doutrina.

$\mathrm{O}$ administrador de instituição financeira, nesse sentido, tem uma função ainda mais complexa e delicada. A importância das instituições financeiras na economia de qualquer país, na qualidade de intermediadoras do fomento das atividades empresariais via concessão de crédito e captadoras de poupança popular, coloca o gestor desses fluxos em uma posição de maior destaque e maior exposição a riscos. Isso porque, além de agir no interesse da instituição financeira - maximizando os ganhos -, deve estar atento, também, ao interesse dos poupadores, investidores e tomadores de crédito - sob pena de colocar em risco a economia nacional. Por se encontrar nessa posição estratégica, o estudo da responsabilidade civil desses profissionais, especialmente em situações de crise das instituições financeiras, torna-se especialmente relevante e interessante.

Partindo de uma análise histórica da atividade bancária no Brasil e dos métodos de saneamento de crises das instituições financeiras no país - capitaneados pelo Banco Central do Brasil - o presente estudo pretende explorar a natureza, os limites e as consequências da responsabilidade civil dos administradores dessas instituições, tal como estabelecido pela Lei ${ }^{0}$ 6.024/74. Para tanto, será mapeada a discussão acerca da responsabilização objetiva e subjetiva na doutrina e na jurisprudência pátria. Filiando-se a parte da doutrina, este trabalho conclui pela natureza subjetiva da responsabilidade civil dos administradores de instituições financeiras, existindo espaço para soluções intermediárias, como a inversão do ônus probatório - carreando-o ao administrador - como já delineado em jurisprudência do Superior Tribunal de Justiça. Essa posição ensejará uma revisão crítica do atual texto da Lei $\mathrm{n}^{\mathrm{o}}$ 6.024/74 e possibilitará uma reflexão para futuras alterações legislativas, inclusive sob o ponto de vista de um ambiente negocial altamente regulado.

Por fim, a contraposição do sistema brasileiro com a doutrina e a jurisprudência norte-americana sobre o tema, com o objetivo de verificar, comparativamente, como os parâmetros de responsabilização dos administradores de instituições financeiras daquele país - que foi o epicentro da pior crise bancária da atualidade.

Palavras chave: Responsabilidade Civil - Administradores - Instituições Financeiras Regimes Especiais - Banco Central do Brasil 



\section{ABSTRACT}

If it were possible to summarize the role of the executive officer of any company, the description of her tasks would be the management of flows and assets, aiming to deliver the products and services, the permanence of company in the market and profit. In short, the executive officer is one of the main responsible for the success of any enterprise. For this reason, the study of the legal responsibility of this professional has always aroused great interest among legal scholars.

Therefore, the executive officer of a financial institution has an even more complex and delicate function. The importance of financial institutions in the economy of any country, as promoters of entrepreneurial activities through credit granting and keepers of common people savings, places the manager of these flows in a position of greater prominence and greater exposure to risks. This is because, in addition to acting in the interest of the financial institution - maximizing its profits - she must also be concicous of the interests of savers, investors and borrowers - otherwise the national economy may be put at risk. Because she is in this strategic position, the study of civil liability of these professionals, especially in situations of crisis of the financial institutions, becomes especially relevant and interesting.

Beginning with a historical analysis of banking activity in Brazil and the methods for reorganizing financial institutions in Brazil - led by Brazilian Central Bank - the present study intends to explore the nature, limits and consequences of executive officer's civil liability as established by Act $n^{0}$ 6.024/74. In order to do so, the study shall map the discussion on objective and subjective liability of such professionals in Brazilian legal scholars opinion. This work comes to the conclusion that banks executive officer's professional liability is subjective and, as such, must be verified according to parameters of behavior established by law and by the Courts. There is also room for intermediary solutions, such as the reversal of the burden of proof - assigning it to the officer - as already outlined in Brazilian Superior Court of Justice's decisions. This position will provide a critical review of the current text of Act $\mathrm{n}^{\circ}$ 6.024/74 and will allow for reflection on future legislative changes, considering a highly regulated business environment.

At last, the comparison of Brazilian legal system with American legal scolars opinions and the American Court's decisions on the subject, will serve to compare the parameters of liability of the banks executives officer's - considering that U.S.A. was the epicenter the worst modern banking crisis.

Key words: Civil Liability - Executive officer - Special Regimes - Brazilian Central Bank 



\section{LISTA DE ABREVIATURAS E SIGLAS}

BACEN

CVM

$C F P B$

FDIC

PROER

RAET

SUMOC

$U D A A P$

Código Civil ou Código Civil de 2002

Código Civil de 1916

Código de Processo Civil de 2015

Constituição Federal de 1988

Antiga Lei de Falências

Dodd-Frank

FIRREA

U.S.C.

Decreto-lei no 685/69.

Lei ${ }^{\circ} 4.595 / 64$

Lei $\mathrm{n}^{\mathrm{o}} 6.404 / 76$ ou Lei das S.A.

Lei ${ }^{\circ} 6.024 / 74$
Banco Central do Brasil

Comissão de Valores Mobiliários

Consumer Financial Protection Bureau

Federal Deposit Insurance Corporation

Programa de Estímulo à Reestruturação e ao Fortalecimento do Sistema Financeiro Nacional

Regime de Administração Especial Temporária Superintendência da Moeda e do Crédito

Unfair, deceptive, or abusive acts and practices

Brasil. Lei $\mathrm{n}^{\circ} 10.406$, de 10 de janeiro de 2002

Brasil. Lei $\mathrm{n}^{\circ} 10.406$, de 10 de janeiro de 2002

Brasil. Lei $\mathrm{n}^{\mathrm{o}}$ 13.105, de 16 de março de 2015

Brasil. Constituição da República Federativa do Brasil de 1988

Brasil. Decreto-lei no 7.661 de 21 de junho de 1945

Estados Unidos. Dodd-Frank Wall Street Reform and Consumer Protection Act

Estados Unidos. Financial Institutions Reform, Recovery, and Enforcement Act

Estados Unidos. United States Code

Brasil. Decreto-lei $n^{0}$ 685, de 17 de julho de 1969.

Brasil. Lei n ${ }^{\circ} 4.595$, de 31 de dezembro de 1964 Brasil. Lei n ${ }^{\circ}$ 6.404, de 15 de dezembro de 1976 Brasil. Lei no 6.024, de 13 de março de 1974 
Lei $n^{\circ} 6.385 / 76$

Lei $\mathrm{n}^{\circ} 9.447 / 97$

Lei $\mathrm{n}^{\mathrm{o}} 1.808 / 53$

Lei $n^{\circ} 11.101 / 05$

STJ

TJSP
Brasil. Lei ${ }^{\circ}$ 6.385/76, de 07 de dezembro de 1976

Brasil. Lei no 9.447, de 14 de março de 1997

Brasil. Lei $\mathrm{n}^{\circ}$ 1.808, de 7 de janeiro de 1953

Brasil. Lei $\mathrm{n}^{\circ}$ 11.101, de 09 de fevereiro de 2005

Superior Tribunal de Justiça

Tribunal de Justiça do Estado de São Paulo 


\section{SUMÁRIO}

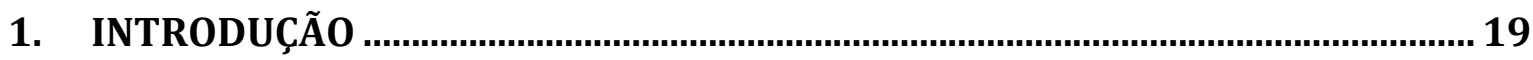

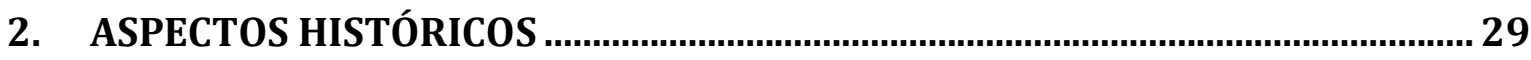

2.1. BREVE HISTÓRICO DA ATIVIDADE BANCÁRIA NO BRASIL ..................................29

2.2. EVOLUÇÃO DOS MÉTODOS DE INTERVENÇÃO DO ESTADO BRASILEIRO NAS

INSTITUIÇÕES FINANCEIRAS EM CRISE.............................................................................34

2.3. EVOLUÇÃO LEGISLATIVA DA RESPONSABILIDADE CIVIL DOS

ADMINISTRADORES DE INSTITUIÇÕES FINANCEIRAS........................................................44

3. A CRISE DAS INSTITUIÇÕES FINANCEIRAS E A DECRETAÇÃO DOS REGIMES

ESPECIAIS PELO BANCO CENTRAL DO BRASIL.................................................... 49

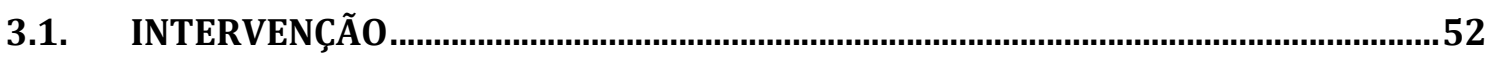

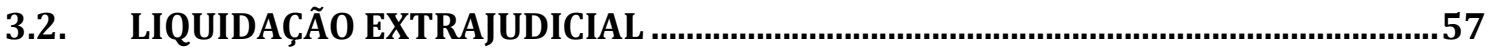

3.3. REGIME DE ADMINISTRAÇÃO TEMPORÁRIA (RAET) ............................................63

3.4. FALÊNCIA DE INSTITUIÇõES FINANCEIRAS...........................................................65

4. A RESPONSABILIDADE CIVIL DOS ADMINISTRADORES DE INSTITUIÇÕES

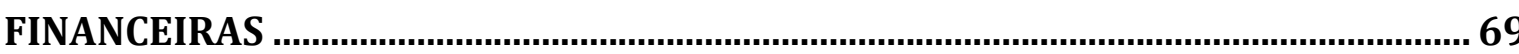

4.1. A RESPONSABILIDADE CIVIL DOS ADMINISTRADORES DE SOCIEDADES

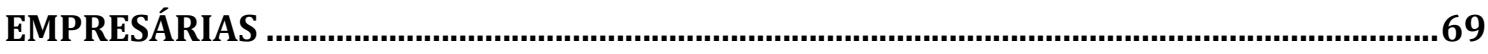

4.2. A RESPONSABILIDADE CIVIL DOS ADMINISTRADORES DE INSTITUIÇÕES

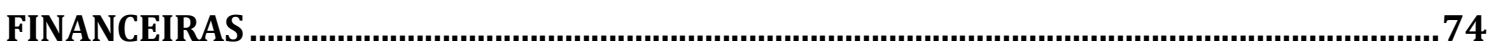

4.2.1. O Posicionamento da doutrina brasileira ...................................................................74

4.2.2. O Posicionamento da jurisprudência...................................................................92

4.3. CONSIDERAÇõES ACERCA DO PROCEDIMENTO PARA RESPONSABILIZAÇÃO DOS ADMINISTRADORES E CONTROLADORES DE INSTITUIÇÕES FINANCEIRAS E A DISCUSSÃO SOBRE A INDISPONIBILIDADE DE BENS.

5. A RESPONSABILIDADE CIVIL DOS ADMINISTRADORES DE INSTITUIÇÕES FINANCEIRAS EM CRISE NO DIREITO NORTE-AMERICANO: UMA ANÁLISE DE DIREITO ESTRANGEIRO

5.1. FONTES DA RESPONSABILIDADE DO ADMINISTRADOR: LEIS FEDERAIS E PRECENDENTES VINCULANTES.

5.2. OS PRECENDENTES SOBRE PARÂMETROS PARA AFERIÇÃO DA

RESPONSABILIDADE DOS ADMINISTRADORES DE INSTITUIÇÕES FINANCEIRAS .... 112

5.3. LEGITIMIDADE PARA PLEITEAR A RESPONSABILIZAÇÃO DOS

ADMINISTRADORES E DIRETORES DE INSTITUIÇÕES FINANCEIRAS

5.4. REGRAS INTERNAS DO FDIC PARA AFERIR A RESPONSABILIDADE DOS ADMINISTRADORES E DIRETORES DE INSTITUIÇÕES FINANCEIRAS E AJUIZAR AÇõES COM TAL CAUSA DE PEDIR.

5.5. ALGUNS DADOS SOBRE A ATUAÇÃO DO FDIC NA RESPONSABILIZAÇÃO DE DIRETORES E ADMINISTRADORES DE INSTITUIÇÕES FINANCEIRAS NOS ÚLTIMOS ANOS 121

6. CRÍTICAS À LEI № 6.024/74 E PERSPECTIVAS DE ALTERAÇõES 
LEGISLATIVAS

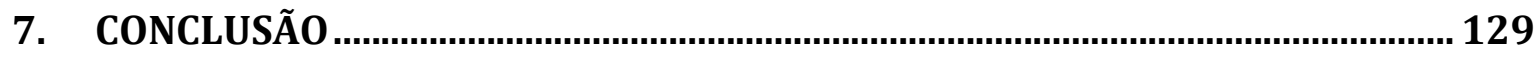

8. BIBLIOGRAFIA 


\section{INTRODUÇÃO}

As instituições financeiras desempenham papel fundamental na economia de qualquer país. No Brasil, essas sociedades são caracterizadas por lei pela captação, intermediação e/ou aplicação de recursos financeiros próprios ou de terceiros, em moeda nacional ou estrangeira, e pela custódia de valores de propriedade de terceiros, conforme estabelecido pelo artigo 17 da Lei no 4.595, de 31 de dezembro de $1964^{1}$ (“Lei n 4.595/64”).

Nesse sentido, as instituições financeiras são responsáveis pela circulação do dinheiro na economia, sendo intermediárias das operações de pagamentos realizadas entre particulares dentro de um mesmo país e, também, para fora dele.

Cabe ressaltar, contudo, que o papel das instituições financeiras vai além da intermediação de pagamentos e encontra sua função primordial na captação de recursos no mercado e na consequente concessão de créditos, sempre com o intuito de auferir o lucro. São entidades estratégicas na condução da economia dos Estados democráticos, na medida em que são responsáveis pela circulação da moeda, pelos financiamentos dos grandes projetos socioeconômicos intentados pelos governos e, também, para a subvenção do empreendedorismo por particulares.

Assim, em um panorama geral, a atividade bancária é tão relevante para a condução da economia que o Estado teve que criar mecanismos para o seu controle e direcionamento, tornando-se ele próprio também um banqueiro ${ }^{2}$, ao intermediar operações entre as instituições financeiras em atividade no território nacional. Essas são algumas das funções atribuídas ao BACEN, às quais se somam as que mais serão tratadas ao longo deste trabalho: a regulação e fiscalização das atividades bancárias, sobretudo o controle exercido nas crises das instituições financeiras, através dos mecanismos de intervenção, liquidação extrajudicial e regime de

\footnotetext{
${ }^{1}$ Art. 17. Consideram-se instituições financeiras, para os efeitos da legislação em vigor, as pessoas jurídicas públicas ou privadas, que tenham como atividade principal ou acessória a coleta, intermediação ou aplicação de recursos financeiros próprios ou de terceiros, em moeda nacional ou estrangeira, e a custódia de valor de propriedade de terceiros.

${ }^{2}$ ABRÃO, Nelson. Direito Bancário. 14a ed. São Paulo: Saraiva, 2011. p. 38.
} 
administração especial temporária ("RAET”).

As instituições financeiras, na qualidade de entidades estratégicas do sistema financeiro nacional, capazes de impactar de forma direta na economia do Estado, na medida em que são captadoras e fornecedoras de recursos, devem ser fiscalizadas com atenção a fim de evitar que problemas políticos ou de gestão, fraudes e a assunção de riscos excessivos levem a instituição financeira a uma crise irreversível, que atingirá diretamente seus credores e, reflexamente, a sociedade e a economia nacional - e por vezes internacional.

Recentemente pudemos verificar o quão impactante para o mercado internacional e para a sociedade pode ser uma crise financeira centrada na quebra do vínculo de confiança dos investidores na solidez das instituições que integram o mercado financeiro. A crise de 2008, iniciada nos EUA, decorrente do excesso de concessão de crédito de alto risco, levou a quebra de importantes bancos ${ }^{3}$, fragilizou a liquidez de várias instituições ${ }^{4}$, desestabilizou a economia de diversos países e a elevação da taxa de desemprego nos EUA e na Europa ${ }^{5}$. Esse quadro levou o governo americano a intervir diretamente na economia para salvar as principais instituições financeiras do país ("bail out"), seguindo a doutrina "too big to fail" 6 .

\footnotetext{
${ }^{3}$ A quebra do banco investimento Lehman Brothers causou um sério impacto nacional e sistêmico. Já a falência de cerca de 380 bancos comerciais por todo o território norte-americano teve impacto direto na vida dos correntistas e poupadores nos 51 estados daquele país. A lista dos bancos que quebraram pode ser acessada no endereço virtual do Federal Deposit Insurance Corporation (FDIC): https://www.fdic.gov/bank/individual/failed/banklist.html , consultado em 12.12.2017.

${ }^{4}$ A exemplo do impacto sofrido por outro banco de investimento de importância capital na economia americana Merrill Lynch - cuja operação foi comprada pelo banco comercial Bank of America: https://www.theguardian.com/business/2008/sep/15/merrilllynch.wallstreet, consultado em 4.1.2017.

5 http://oglobo.globo.com/economia/na-uniao-europeia-10-milhoes-estao-desempregados-ha-mais-de-um-ano9603458, (Consultado em 4.6.2016)

${ }^{6}$ Too big to fail (em tradução livre: grande demais para falir) é a expressão usada para descrever determinadas empresas que se tornaram de tal forma grandes e engendradas na base da economia de um país que o governo intervirá para impedir sua falência, uma vez que sua quebra teria um catastrófico efeito dominó.Trata-se de uma análise de custo-benefício para o governo, em que a ajuda financeira (ou bailout) a tais empresas é menos custosa para os cofres públicos que os efeitos de sua crise - e de uma consequente crise sistêmica. O termo surgiu em meados da década de 80, popularizado pelo deputado Stewart McKinney, por ocasião da quebra do Continental Illinois National Bank and Trust Company.

Os grandes bancos e seguradoras são, em várias situações, considerados grandes demais para quebrar. Na crise do subprime, deflagrada em 2008 nos Estados Unidos da América, o governo americano desembolsou mais de US\$ 700 bilhões para salvar grandes bancos atingidos pela crise e a AIG - seguradora que segurava boa parte desses bancos - da falência iminente, uma vez que a quebra de tais instituições poderia causar uma crise financeira nacional (quiçá mundial) sem precedentes. Sobre o tema, ver https://www.investopedia.com/terms/t/too-big-tofail.asp; https://www.ft.com/content/0bd8f4d4-76de-11e7-a3e8-60495fe6ca71, (Consultados em 4.1.2018).
} 
Esse cenário demonstra que a regulação e fiscalização da atividade financeira é medida necessária para proteção não somente da economia e dos mercados, mas também dos poupadores e dos investidores e, por fim, da própria sociedade. Por esse motivo, esse estudo adotará a premissa de que, para evitar que o BACEN chegue à decretação dos regimes especiais das instituições financeiras, é imprescindível que haja um controle sobre a regularidade de da atividade destas últimas no mercado, afastando-se a teoria do free banking - conceito minoritário no pensamento econômico-jurídico, segundo a qual os bancos deveriam agir na economia sem regulação ou supervisão. Sobre o tema, melhor orienta o Prof. Haroldo Malheiros Duclerc Verçosa:

Para esse efeito, os bancos centrais exercem a competência normativa, preventiva, fiscalizadora e repressiva delegada (na área administrativa e dentro dos limites determinados pela lei), autorizando o funcionamento dos bancos; regulando e fiscalizando suas atividades; e julgando os atos irregulares e aplicando as penalidades cabíveis ${ }^{7}$.

No Brasil a experiência tem mostrado que mesmo as instituições financeiras tradicionais e de boa reputação são passíveis de instabilidades, comprovando a importância e o delicado equilíbrio das entidades que atuam nesse mercado, bem como a necessidade de regulação e fiscalização do setor. São exemplos os casos dos bancos Econômico, Nacional, Banerj, Banespa, Bamerindus, Santos, BVA e Cruzeiro do Sul.

Nesse aspecto, a responsabilização civil dos administradores de instituições financeiras, prevista especificamente nos artigos 39 e seguintes da Lei $n^{\circ}$ 6.024, de 13 de março de 1974 ("Lei $\mathrm{n}^{\circ}$ 6.024/74") - e tema central deste trabalho - destaca-se como um dos mecanismos de inibição de fraudes e gestão temerárias das instituições financeiras e, em última análise, é um instrumento para garantir a saúde de tais sociedades.

Para além da prevenção da conduta temerária na gestão de instituições financeiras, a qual coloca em risco o patrimônio alheio, a responsabilização civil dos administradores

\footnotetext{
${ }^{7}$ VERÇOSA, Haroldo Malheiros Duclerc. Bancos Centrais do Direito Comparado. São Paulo: Malheiros, 2005. p.71.
} 
também se destina a garantir a indenização pelos prejuízos causados à companhia em razão de seus atos.

O Estado, preocupado com as consequências catastróficas da má administração de instituições financeiras, não mediu esforços para regular a responsabilização dos integrantes da administração e direção dessas entidades ${ }^{8}$. Nesse sentido, a responsabilidade civil aplicada aos administradores de sociedades empresárias é tema tratado em vários diplomas, haja vista sua importância de regulação.

Tem-se assim que, de forma mais genérica, o tema da responsabilidade civil dos administradores é tratado ao longo do Código Civil, notadamente em seus artigos 186, 927, 1015 e 1016. Também é disciplinada nos artigos 158 e seguintes da Lei $\mathrm{n}^{\circ}$ 6.404, de 15 de dezembro de 1976 ("Lei $n^{\circ}$ 6.404/76"), que trata especificamente dos administradores das sociedades por ações.

A responsabilidade civil dos administradores de instituições financeiras, por sua vez, é especificamente regulada pela Lei $n^{0}$ 6.024/74, que dispõe sobre os regimes de intervenção, liquidação extrajudicial e regime de administração especial temporária das instituições financeiras.

Note-se, contudo, que apesar da importância da matéria e do seu largo tratamento legislativo, não são muitas as obras que empenharam esforços em tratar da natureza e extensão da responsabilidade civil dos administradores de instituições financeiras, fato que, aliado à notoriedade das decretações de regimes especiais de instituições financeiras realizadas pelo BACEN e às investigações de seus administradores havidas nas últimas décadas, contribuíram de forma decisiva para a escolha do tema do presente estudo.

Diante da perspectiva de alteração da legislação que trata da matéria, já em discussão no âmbito do BACEN, os debates acerca da necessidade de atualização da legislação atualmente

\footnotetext{
${ }^{8}$ ABRÃO, Nelson. Direito Bancário. 14ª ed. São Paulo: Saraiva, 2011. p. 302.
} 
em vigor no país se intensificaram, tornando oportuno o tratamento sobre seus aspectos mais polêmicos à luz das diferentes propostas de "lege ferenda" encontradas na doutrina que se pretende demonstrar ao longo deste trabalho.

Um dos pontos mais debatidos ao longo dos mais de 40 anos de vigência da atual Lei $n^{\circ}$ 6.024/74 entre os doutrinadores que estudaram o tema - e que possivelmente será alvo de modificações tão logo haja a prometida renovação da legislação - diz respeito à responsabilidade civil dos administradores de instituições financeiras, notadamente nos artigos 39 e 40:

Art. 39. Os administradores e membros do Conselho Fiscal de instituições financeiras responderão, a qualquer tempo, salvo prescrição extintiva, pelos atos que tiverem praticado ou omissões em que houverem incorrido.

Art. 40. Os administradores de instituições financeiras respondem solidariamente pelas obrigações por elas assumidas durante sua gestão, até que se cumpram.

Parágrafo único. A responsabilidade solidária se circunscreverá ao montante e dos prejuízos causados.

Em uma análise perfunctória dos artigos supracitados, precipitando aqui parte da discussão que se travará nos capítulos subsequentes, seria possível notar uma aparente contradição entre os dois dispositivos. Isso porque o artigo 39 determina que os administradores de instituições financeiras responderão pelos atos ou omissões que tiverem praticado no exercício do cargo, insinuando uma responsabilidade de cunho subjetivo desses administradores em relação aos prejuízos causados, sendo necessária a apuração do dolo ou culpa nas condutas dos citados profissionais que acabarem por prejudicar a saúde financeira das instituições a que serviam.

Em contrapartida, na redação do artigo 40, que determina que os administradores respondem solidariamente pelas obrigações assumidas pelas instituições financeiras, pode-se interpretar que a responsabilidade imputada aos administradores tem caráter objetivo, uma vez que textualmente estabelece que a responsabilidade do profissional em questão é solidária com a da instituição financeira e integral - ou seja, só cessa com o total cumprimento das obrigações 
assumidas pela instituição financeira no curso de sua gestão.

Nesse sentido, a promulgação da Lei $n^{0}$ 6.024/74, trouxe à tona esse debate ao revogar a Lei $n^{\circ} 1.808$, de 7 de janeiro de 1953 (“Lei $n^{\circ} 1.808 / 53$ ”) - que dispunha claramente em seu artigo $2^{\circ}$ que os administradores, agindo com culpa ou dolo, responderiam solidariamente pelas obrigações assumidas pelas instituições financeiras durante a sua gestão9 .

Por ocasião da promulgação da Lei $n^{0}$ 6.024/74 colocou-se a discussão na doutrina sobre a natureza da responsabilidade dos administradores de instituições financeiras. Para alguns, como Modesto Carvalhosa ${ }^{10}$ e Haroldo Malheiros Duclerc Verçosa ${ }^{11}$, a responsabilidade seria objetiva, em razão do risco criado no exercício da atividade.

Em sentido contrário, para outra corrente doutrinária que tem como um de seus representantes Arnoldo Wald, a responsabilidade continuaria a ser subjetiva mesmo após a alteração legislativa, na medida em que a responsabilidade solidária do administrador nas obrigações assumidas pela instituição, prevista no artigo 40, partiria do pressuposto de que as obrigações seriam decorrentes de atos ou omissões do administrador, interpretando os dispositivos conjuntamente ${ }^{12}$.

O entendimento da doutrina ainda não é plenamente pacífico. Na jurisprudência, por outro lado, por muitos anos consolidou-se o entendimento de que a responsabilidade civil dos administradores de instituições financeiras tem caráter subjetivo. Mais recentemente, no entanto, o STJ tem encabeçado uma mudança na interpretação legislativa, que começa a ser adotada nos demais tribunais brasileiros, segundo a qual a responsabilidade prevista na Lei $n^{\circ} 6.024 / 74$ seria

\footnotetext{
9 “Art. $2^{\circ}$ Respondem solidariamente pelas obrigações assumidas pelos bancos e casas bancarias durante a sua gestão e até que elas se cumpram, os diretores e gerentes que procederem com culpa ou dolo, ainda que se trate de sociedade por ações, ou de sociedade por cotas, de responsabilidade limitada.

Parágrafo único. A responsabilidade se circunscreverá ao montante dos prejuízos causados, pela inobservância do disposto nesta lei, sempre que for possível fixá-la."

${ }^{10}$ CARVALHOSA, Modesto. Responsabilidade Civil dos Administradores das Companhias Abertas, Revista de Direito Mercantil, Industrial, Econômico e Financeiro, n. 49. São Paulo: RT, 1983. p.19-20.

${ }^{11}$ VERÇOSA, Haroldo Malheiros Duclerc Verçosa. Responsabilidade civil especial nas instituições financeiras e nos consórcios em liquidação extrajudicial. São Paulo: RT, 1993. p. 86-87.

${ }^{12}$ WALD, Arnoldo. A culpa e o risco como fundamento da responsabilidade pessoal do diretor do Banco. Revista de direito mercantil, industrial, economico e financeiro. Nova Série, v. 15, n. 24, 1976. p. 36.
} 
de natureza subjetiva ${ }^{13}$.

Portanto, a discussão acerca da natureza da responsabilidade civil especial dos administradores de instituições financeiras é o assunto central que se pretende aprofundar no presente trabalho, buscando aferir qual entendimento estaria mais alinhado à realidade econômica atual e o aumento na complexidade das relações jurídicas nessa seara, haja vista os 40 anos de vigência da Lei $n^{\circ} 6.024 / 74$ completados em 2014 e as perspectivas de novas alterações legislativas.

A problemática do tema também envolve saber a extensão dessa responsabilidade, quem são os administradores aos quais a lei se refere e em que termos seus patrimônios devem responder pelo prejuízo da instituição financeira.

A esse respeito, como já sedimentado na doutrina e jurisprudência ${ }^{14}$, o artigo 145 da Lei $6.404 / 76^{15}$ entende que os conselheiros e diretores são considerados administradores para os efeitos legais, razão pela qual também são abarcados pelos artigos 39 e 40 da Lei 6.024/74. Não é diferente o tratamento dispensado pela legislação ao controlador da instituição financeira. O artigo $1^{\circ}$ da Lei $n^{\circ}$ 9.447, de 14 de março de 1997 (“Lei no 9.447/97”) inclui, expressamente, a responsabilidade civil solidária dos controladores das instituições sob regime especial ${ }^{16}$.

Contudo, a responsabilização objetiva desses profissionais deve ser vista com a devida cautela, como também destaca o Prof. Haroldo Malheiros Duclerc Verçosa. A atenção se deve ao fato de que há diretores-empregados - ou seja, administradores-profissionais, contratados pelo controlador para assumirem áreas técnicas da instituição sob suas ordens e sujeitos a demissão. Esses profissionais muitas vezes dirigem um determinado setor da instituição,

\footnotetext{
${ }^{13}$ STJ, REsp no 447.939, $3^{\text {a }}$ Turma, Rel. Min. Nancy Andrighi, j. 25.10.2007.

${ }^{14}$ VERÇOSA, Haroldo Malheiros Duclerc. A Responsabilidade Civil Especial das Instituições Financeiras Insolventes, in SADDI, Jairo (org.). Intervenção e Liquidação Extrajudicial no Sistema Financeiro Nacional. São Paulo: Textonovo, 1999. p. 158.

15 “Art. 145. As normas relativas a requisitos, impedimentos, investidura, remuneração, deveres e responsabilidade dos administradores aplicam- se a conselheiros e diretores."

16 "Art. $1^{\circ}$ A responsabilidade solidária dos controladores de instituições financeiras estabelecida no art. 15 do Decreto-lei no 2.321, de 25 de fevereiro de 1987, aplica-se, também, aos regimes de intervenção e liquidação extrajudicial de que trata a Lei $n^{\circ}$ 6.024, de 13 de março de 1974.”.
} 
desconhecendo, em sua totalidade, os atos praticados pelas demais áreas da companhia ${ }^{17}$.

Não é difícil imaginar, portanto, que esses profissionais não se enquadram exatamente no fundamento jurídico da responsabilidade objetiva, ou seja, o binômio do risco e o seu proveito $^{18}$, por não participarem de forma direta e linear nos resultados da instituição financeira. Nesse sentido, o causador de eventual prejuízo a terceiros em razão da assunção de elevado risco com o objetivo de auferir vantagem econômica é o sujeito a quem idealmente se deve responsabilizar.

Para além da natureza e da extensão da responsabilidade civil especial dos administradores de instituições financeiras em liquidação extrajudicial, importante trazer à pesquisa a discussão sobre constitucionalidade da Lei $n^{\circ}$ 6.024/74 e a sua eventual recepção pela Constituição de 1988, sobretudo no que diz respeito aos seus artigos $36^{19}$ e seguintes que tratam

\footnotetext{
17 VERÇOSA, Haroldo Malheiros Duclerc. A Responsabilidade Civil Especial das Instituições Financeiras Insolventes, in SADDI, Jairo (org.). Intervenção e Liquidação Extrajudicial...Op. Cit., p. 158.

${ }^{18}$ De acordo com José Fernando Simão "o novo Código Civil, em seu artigo 927, parágrafo único, preceitua que haverá a obrigação de indenizar, independentemente de culpa, nos casos previstos em lei, ou quando a atividade desenvolvida pelo autor do dano implicar, por sua natureza, risco para os direitos de outrém. Assim, o novo diploma afasta a teoria da culpa e expressamente adota a Teoria do Risco, chamada de objetiva, segundo a qual aquele que em virtude de sua atividade cria um risco de danos a terceiro, fica obrigado a reparar, sendo irrelevante que a ação do agente denote imprudência ou negligência." in A teoria do risco no novo Código Civil, disponível em http://professorsimao.com.br/artigos simao a teoria do risco.htm, consultado em 4.1.2018. A teoria do risco foi subdividida em algumas categorias como a teoria do risco integral, do risco profissional, entre outras. No presente estudo, tratar-se-á da teoria do risco proveito, que rege atividades lucrativas, como a atividade bancária. Em poucas palavras, determina a teoria do risco proveito que o responsável pelos prejuízos causados a terceiros é aquele que se beneficia das atividades de risco. Assim, o agente, que se locupleta dos resultados favoráveis de determinada atividade deve, sem a necessidade de apuração de culpa, reparar os danos causados a outrem no exercício da atividade em questão". Sobre o tema ver: NADER, Paulo. Curso de direito civil, responsabilidade civil, volume VII, Rio de Janeiro: Forense, 2009; DENARI, Zelmo. Da Qualidade de Produtos e Serviços, da Prevenção e da Reparação de Danos. In: GRINOVER, Ada Pellegrini et al. Código Brasileiro de Defesa do Consumidor Comentado pelos Autores do Anteprojeto. 10a ed. Rio de Janeiro: Forense, 2011. p. 195-196.

19 “Art . 36. Os administradores das instituições financeiras em intervenção, em liquidação extrajudicial ou em falência, ficarão com todos os seus bens indisponíveis não podendo, por qualquer forma, direta ou indireta, aliená-los ou onerá-los, até apuração e liquidação final de suas responsabilidades.

$\S 1^{\circ} \mathrm{A}$ indisponibilidade prevista neste artigo decorre do ato que decretar a intervenção, a extrajudicial ou a falência, atinge a todos aqueles que tenham estado no exercício das funções nos doze meses anteriores ao mesmo ato.

$\S 2^{\circ}$ Por proposta do Banco Central do Brasil, aprovada pelo Conselho Monetário Nacional, a indisponibilidade prevista neste artigo poderá ser estendida:

a) aos bens de gerentes, conselheiros fiscais e aos de todos aqueles que, até o limite da responsabilidade estimada de cada um, tenham concorrido, nos últimos doze meses, para a decretação da intervenção ou da liquidação extrajudicial,

b) aos bens de pessoas que, nos últimos doze meses, os tenham a qualquer título, adquirido de administradores da instituição, ou das pessoas referidas na alínea anterior desde que haja seguros elementos de convicção de que se trata de simulada transferência com o fim de evitar os efeitos desta Lei.

$\S 3^{\circ}$ Não se incluem nas disposições deste artigo os bens considerados inalienáveis ou impenhoráveis pela
} 
da indisponibilidade de bens dos administradores.

$\mathrm{O}$ artigo 36 da Lei $\mathrm{n}^{\mathrm{o}}$ 6.024/74 determina que os bens dos administradores de instituições financeiras em regime especial fiquem indisponíveis até a devida apuração final de suas responsabilidades pelo relatório do BACEN. Nesse aspecto, muito embora seja dado vista ao interessado dos autos do processo administrativo movido pelo BACEN para investigação de responsabilidades, não há uma análise efetiva de mérito de sua defesa ${ }^{20}$.

Para parte da doutrina, como será discutido neste estudo, a dinâmica estabelecida no processo administrativo instaurado pelo BACEN e a defesa franqueada ao administrador nessa esfera, fere o corolário constitucional do devido processo legal, consubstanciado no binômio da ampla defesa e do contraditório ${ }^{21}$. Entre outros motivos porque, uma vez determinada a indisponibilidade dos bens dos administradores, por ocasião da decretação do ato que institui o regime especial da instituição financeira, ela pode se perdurar por anos até que se julgue a ação de responsabilidade civil eventualmente movida pelo Ministério Público, privando os administradores de seus bens em desacordo com o quanto estabelecido pelo artigo $5^{\circ}$, LV da Constituição Federal de 1988.

Diante disso, é importante uma análise mais aprofundada do tema para aferir se a Lei $n^{\circ} 6.024 / 74$ foi de fato recepcionada pela Constituição de 1988 e se está alinhada com o Código Civil de 2002 e Código de Processo Civil de 2015.

Os esforços da pesquisa, portanto, devem se concentrar na análise da natureza e extensão da responsabilidade civil dos administradores de instituições financeiras nos regimes especiais decretados pelo BACEN, assim como na constitucionalidade da Lei $n^{\circ} 6.024 / 74$ que os

\footnotetext{
legislação em vigor.

$\S 4^{\circ}$ Não são igualmente atingidos pela indisponibilidade os bens objeto de contrato de alienação, de promessa de compra e venda, de cessão de direito, desde que os respectivos instrumentos tenham sido

levados ao competente registro público, anteriormente à data da decretação da intervenção, da liquidação extrajudicial ou da falência."

${ }^{20}$ WALD, Arnoldo. O Descabimento da Indisponibilidade dos Bens dos Ex-administradores de Instituição Financeira em Liquidação Extrajudicial, in SADDI, Jairo (org.). Intervenção e Liquidação Extrajudicial no Sistema Financeiro Nacional. São Paulo: Textonovo, 1999. p. 184.

${ }^{21}$ WALD, Arnoldo. O Descabimento da Indisponibilidade dos Bens dos Ex-administradores de Instituição Financeira em Liquidação Extrajudicial, in SADDI, Jairo (org.). Intervenção e Liquidação Extrajudicial ... $O p$. Cit., p. 184.
} 
regulamentam.

No entanto, para que se chegue ao principal objeto deste trabalho com o devido esteio doutrinário e legislativo, o estudo se inicia com uma breve remissão histórica que retoma o conceito de instituição financeira e a sua importância para a economia de qualquer Estado, bem como repassa a criação do BACEN e o seu papel para a regulação do mercado financeiro nacional. Tais informações são indispensáveis para compreender o tratamento das instituições financeiras em situação de crise e o impacto para seus administradores e controladores.

Em seguida, serão analisadas cada uma das formas de ingerência do BACEN em instituições financeiras em crise, possibilitando a solução do problema - seja com o saneamento das finanças da entidade em questão ou com sua retirada organizada e paulatina do mercado com o mínimo impacto para os poupadores, investidores e, em última análise, para a sociedade.

Realizada essa primeira incursão teórica nos temas que estão na base da discussão central deste estudo, passar-se-á a discutir a responsabilidade civil dos administradores como um todo e, de forma específica, dos administradores e controladores de instituições financeiras - como já se disse, com o objetivo de aferir qual a natureza de tal reponsabilidade e quais os desdobramentos dessa configuração jurídica no panorama econômico atual.

Como são consectários do tema principal, serão abordados, na sequência, a problemática do bloqueio e indisponibilidade de bens dos administradores e controladores em razão da crise das instituições a que serviam.

O tema que se pretende enfrentar é vasto, razão pela qual não se tem a ambição de que o trabalho ora apresentado tenha esgotado todas as nuances atinentes à matéria. Tentou-se abarcar com este estudo os assuntos mais importantes que envolvem o tema, tomando-se a cautela de observar que a legislação em vigor está possivelmente com seus dias contados o que, em certa medida, nos instigou a antever as possíveis modificações à luz das discussões já existentes na doutrina e jurisprudência. 


\section{CONCLUSÃO}

A atividade bancária é alvo de regulamentação especial em decorrência da sua importância estratégica para a econômica do Estado, lidando com a moeda por meio da captação de recursos da poupança popular e oferecimento de crédito para o fomento da atividade econômica nacional. É, portanto, atividade de interesse público, na medida em que uma crise nesse setor é capaz de provocar um efeito nefasto em toda a sociedade.

Nesse contexto, insere-se a reponsabilidade civil dos administradores de instituições financeiras, que, em nosso entendimento, deve necessariamente ser interpretada sob o ponto de vista do interesse público.

Sob essa perspectiva, ao longo deste trabalho buscamos trazer à discussão as diferentes interpretações - doutrinárias e jurisprudenciais - das disposições da Lei $n^{\circ}$ 6.024/74 atinentes à responsabilidade civil dos administradores de instituições financeiras sob os regimes interventivos do BACEN.

Em uma análise sistêmica, conflitando as diversas visões, afiliamo-nos àqueles que entendem que o atual sistema vigente no país, circunscrito na Lei ${ }^{\circ} 6.024 / 74$, incorpora a regra geral da responsabilidade subjetiva aos administradores de instituições financeiras em crise (não controladores).

Assim, o artigo 39 enceta a noção de causalidade no âmbito da responsabilidade civil especial dos administradores de instituições financeiras, reproduzindo a regra geral da responsabilidade subjetiva presente no ordenamento brasileiro. O artigo 40, consequentemente, estabelece a solidariedade entre o administrador e a instituição financeira pelas obrigações assumidas durante a sua gestão, sem prejuízo, para tanto, da verificação da existência de culpa ou dolo. O artigo 40 trata, pois, de um passo adiante da constatação da ação ou omissão do administrador. 
No que tange a responsabilidade civil do controlador da instituição financeira (administradores ou não), no entanto, compartilhamos o entendimento de que deve-se adotar a teoria do risco, na medida em que são esses os sujeitos que verdadeiramente lucram com o risco criado pela atividade financeira.

Independentemente do ponto de vista que se analise a questão, seja sob o enfoque da corrente subjetivista ou objetivista, fato é que, não obstante os mais de 40 anos de vigência da atual legislação, perduram as críticas à sua redação, clareza e método, especialmente com relação à natureza da responsabilidade civil dos administradores de instituições financeiras e à indisponibilidade de bens dos administradores, prevista no artigo 36 da Lei $n^{\circ} 6.024 / 74$.

É inegável que a matéria aqui discutida está atrelada a um dos setores mais relevantes da economia - e um dos mais lucrativos de nosso país - o que torna sensível e merecedora de atenção qualquer proposta de alteração legislativa, que pode levar, direta ou indiretamente à oscilação da taxa de juros, encarecimento do crédito, entre outros. Mas a mudança do atual sistema regrado pela Lei ${ }^{\circ} 6.024 / 74$, não obstante sua sensibilidade, precisa ser enfrentado pelo legislador.

A esse respeito, é de conhecimento do setor financeiro e de estudiosos do tema que há alguns anos o BACEN vem discutindo uma proposta para alteração da legislação atual que regula todo o sistema atinente à crise das instituições financeiras - tendo inclusive debatido a questão no âmbito de seminários internacionais promovidos pelo próprio BACEN em parceria com outras entidades. Contudo, até o momento, essas propostas não saíram do plano do debate.

O texto a que se teve acesso parece ainda não ter logrado êxito em aparar todas as arestas necessárias para atender às críticas dos especialistas no assunto e tornar a legislação mais clara e equilibrada, sendo certo, no entanto, que a conjuntura político-econômica do Brasil nos últimos anos não tem colaborado para a evolução da discussão acerca da responsabilidade civil dos administradores de instituições financeiras em crise.

O presente estudo pretendeu lançar luzes sobre essa discussão, trazendo, inclusive, a 
visão da doutrina e da jurisprudência norte-americanas que, ao se debruçar sobre o tema - no auge da crise do subprime - manteve a orientação pela responsabilidade subjetiva dos administradores, mesmo em situação catastrófica. Entendemos que o legislador pátrio, não obstante as dificuldades supracitadas, deverá enfrentar a questão e, com clareza, definir a corrente a que a legislação brasileira se filiará. 


\section{BIBLIOGRAFIA}

ABRÃO, Nelson. Direito Bancário. 14ª ed. São Paulo: Saraiva, 2011.

ADAMEK, Marcelo Veira Von. Responsabilidade Civil dos Administradores de S/A, São Paulo: Saraiva, 2009.

ações correlatas, São Paulo: Saraiva, 2010.

Responsabilidade civil dos administradores de S/A e as . (Coord.). Temas de Direito Societário e Empresarial

Contemporâneos. São Paulo: Malheiros, 2011.

AGUIAR DIAS, José de. Da responsabilidade civil. $11^{\text {a }}$ ed. Rio de Janeiro: Renovar, 2006.

AMARO, Anderson de Souza. O seguro de responsabilidade civil dos administradores. Revista de Direito Empresarial. São Paulo: RT, vol. 2, p. 97-118, mar. 2014.

BATTIN, Michael P. Banking director liability under FIRREA, Fordham Law Review, V. 63, issue 5, 1995, p. 2349.

BITTAR, Carlos Alberto. Doutrinas essenciais de responsabilidade civil. São Paulo: RT, vol.3, 2011.

BOLLES, Albert S. The duty and liability of banking directors. Yale Law Journal, Vol. 12, No. 5 (Mar., 1903)

BULGARELLI, Waldírio. Responsabilidade dos Administradores das Companhias, in Responsabilidade Civil: doutrina e jurisprudência, coord. CAHALI, Yussef Said, $2^{\mathrm{a}}$ ed., São Paulo: Saraiva, 1988.

. Manual das sociedades anônimas. $8^{\text {a }}$ ed. São Paulo: Atlas, 1996. Tratado de direito empresarial. 29a ed. São Paulo: Atlas, 1995.

. Comentários à lei das sociedades anônimas. Vol. 4. São Paulo:

Saraiva, 1978.

BULHÕES PEDREIRA, José Luiz; LAMY FILHO, Alfredo. Direito das companhias. Vols. I e II. Rio de Janeiro: Forense, 2010.

CARVALHO, Estevão Prado de Oliveira. A responsabilidade dos administradores de instituições financeiras frente aos credores. 119f. Dissertação (mestrado em Direito Civil) sob a orientação do Prof. Dr. Alcides Tomasetti Jr. - Faculdade de Direito da Universidade de São Paulo, São Paulo, 2011. 
CARVAlHOSA, Modesto; EIZIRIK, Nelson. A nova Lei das Sociedades Anônimas. São Paulo: Saraiva, 2002.

CARVALHOSA, Modesto. Comentários à Lei de Sociedades Anônimas. Vol. 3. 2a ed. São Paulo: Saraiva, 1998.

Responsabilidade Civil dos Administradores das Companhias Abertas, Revista de Direito Mercantil Industrial Econômico e Financeiro, São Paulo: RT, no 49, Nova Série, p.14/20, jan.-mar. 1999.

CASTRO, Rodrigo Rocha Monteiro de; WARDE JR., Walfrido Jorge; GUERREIRO, Carolina Dias Tavares (coord.). Direito Empresarial e Outros Estudos em Homenagem ao Professor José Alexandre Tavares Guerreiro, São Paulo: Quartier Latin, 2013.

CAVAlieri FILHO, Sérgio. Programa de Responsabilidade Civil, $4^{\mathrm{a}}$ ed., São Paulo: Malheiros, 2003.

COELHO, Fábio Ulhoa. A responsabilidade civil dos administradores de instituições financeiras. In: MOSQUERA, Roberto Quiroga (Coord.). Aspectos atuais do direito do mercado financeiro e de capitais. São Paulo: Dialética, 1999.

. Curso de direito civil. Vol. 3. São Paulo: Saraiva, 2005.

. Manual de direito comercial. São Paulo: Saraiva, 2002.

COELHO, George Marcondes de Souza. Da liquidação extrajudicial de bancos no direito brasileiro. 111f. Tese de concurso de doutoramento em direito comercial na Faculdade de Direito da Universidade de São Paulo. São Paulo, 1972.

COELHO, Wilson do Egito. Da responsabilidade dos administradores das sociedades por ações em face da nova lei e da Lei 6.024/74. Revista de Direito Mercantil, Industrial, Econômico e Financeiro, São Paulo: RT, nº 40, Nova Série, p. 37-49, out-dez. 1980.

COMPARATO, Fábio Konder. Novos ensaios e pareceres de direito empresarial. Rio de Janeiro: Forense, 1981.

COSTA NETO, Yttrio Corrêa da. Bancos oficiais no Brasil: origem e aspectos de seu desenvolvimento. Brasília: Banco Central do Brasil, 2004.

DE LUCCA, Newton e SIMÃO FILHO, Adalberto (coord.). Comentários à Nova Lei de Recuperação de Empresas e de Falências, São Paulo: Quartier Latin, 2005.

DE LUCCA, Newton. A responsabilidade civil dos administradores de instituições financeiras. Revista de Direito Mercantil, Industrial, Econômico e Financeiro, São Paulo: RT, $n^{0}$ 67, Nova série, p. 32-38, jul.-set.

DELGADO, José Augusto. Liquidação extrajudicial dos bancos. Responsabilidade civil dos seus administradores. Revista de Direito Bancário e do Mercado de Capitais, São Paulo: 
RT, $\mathrm{n}^{\circ}$ 6, ano 2, set.-dez. 1999.

DENARI, Zelmo. Da Qualidade de Produtos e Serviços, da Prevenção e da Reparação de Danos. In: GRINOVER, Ada Pellegrini et al. Código Brasileiro de Defesa do Consumidor Comentado pelos Autores do Anteprojeto. 10a ed. Rio de Janeiro: Forense, 2011.

DE PLÁCIDO e SILVA. Vocabulário jurídico. $15^{\text {a }}$ ed. Rio de Janeiro: Forense, 1999.

DINIZ, Maria Helena. Curso de direito civil brasileiro. 29a ed. vol.7, São Paulo: Saraiva, 2015.

EIZIRIK, Nelson. Instituições Financeiras e Mercado de Capitais: jurisprudência. $2^{\circ}$ tomo, vol. I, Rio de Janeiro: Renovar, 1998.

EIZIRIK, Nelson; GAAL, Ariádna B.; PARENTE, Flávia; HENRIQUES, Marcus de Freitas. Mercado de Capitais - regime jurídico. $2^{\mathrm{a}}$ ed. Rio de Janeiro: Renovar, 2008.

FARIA, Werter Rotunno. Liquidação extrajudicial, intervenção e responsabilidade Civil dos administradores das instituições financeiras. Porto Alegre: Fabris, 1985.

FARIAS, Ricardo Rodrigues. A natureza da responsabilidade civil dos administradores de bancos em regime especial Lei $n^{\circ}$ 6.024/1974 e Decreto-lei $n^{\circ} 2.321 / 1987$. Revista de Direito Bancário e do Mercado de Capitais. São Paulo: RT. vol. 59, p. 65-80, jan. 2013.

FERREIRA, Marcus Vinicius Vita. Indisponibilidade de bens dos ex-administradores de instituições financeiras (arts. 36 e 41 da Lei 6.024/1974). Revista de direito bancário e do mercado de capitais. Ano 12. $\mathrm{n}^{\circ}$ 43. jun.-mar. 2009, p. 245.

FRANCO, Vera Helena de Mello; SZTAJN, Rachel. Falência e Recuperação da Empresa em Crise, Rio de Janeiro: Elsevier, 2008.

Manual de direito comercial. $2^{\mathrm{a}}$ ed., vol. 1. São Paulo: RT,

2004.

FREITAS GOMES, Luiz Roldão de. Da responsabilidade civil dos administradores de instituições financeiras privadas em regime de intervenção e liquidação extrajudicial no Brasil. RF, Rio de Janeiro: Forense, no 228, p. 3.395-3.398, 1984.

GONÇALVES, Carlos Roberto. Responsabilidade civil. 9a ed. São Paulo: Saraiva, 2005.

GONÇALVES NETO, Alfredo de Assis. Manual das companhias ou sociedades anônimas. $3^{\text {a }}$ ed. São Paulo: RT, 2011. p. 219.

GOMES, Orlando. Obrigações. 8a ed. Rio de Janeiro: Forense, 1986.

GUERREIRO, José Alexandre Tavares. Responsabilidade dos administradores de sociedades anônimas. Revista de Direito Mercantil Industrial, Econômico e Financeiro no 42. São Paulo: RT, abr./jun. de 1981, pp. 69-88. 
HAUBRICH, Joseph G. Risk aversion, performance pay and the principal-agent problem, Journal of Political Economy, v. 102, no 2, 1994.

HUBERMAN, Leo. A história da riqueza do homem. $21^{\text {a }}$ ed. Rio de Janeiro: Guanabara, 1986.

LUNDBERG, Eduardo Luís. Rede de proteção e saneamento do sistema bancário. In. SADDI, Jairo (org.). Intervenção e Liquidação Extrajudicial no Sistema Financeiro Nacional 25 anos da Lei 6.024/74, São Paulo: Textonovo, 1999.

Saneamento do sistema financeiro - A experiência brasileira dos últimos 25 anos. In. SADDI, Jairo (org.). Intervenção e Liquidação Extrajudicial no Sistema Financeiro Nacional - 25 anos da Lei 6.024/74, São Paulo: Textonovo, 1999.

MARTINS, Fran. Contratos e obrigações comerciais. Rio de Janeiro: Forense, 2000.

MAXIMILIANO, Carlos. Hermenêutica e aplicação do direito. $16^{a}$ ed. Rio de Janeiro: Forense, 1996.

MELLO FRANCO, Vera Helena de. Manual de direito comercial. $2^{\mathrm{a}}$ ed., vol. 1. São Paulo: RT, 2004.

MOTTA, Nelson Cândido. Da responsabilidade patrimonial dos administradores de instituições financeiras. A indisponibilidade de bens, Revista de Direito Mercantil Industrial Econômico e Financeiro, São Paulo: RT, nº 27, Nova Série, p. 35-53, 1978.

NADER, Paulo. Curso de direito civil, responsabilidade civil, vol. VII, Rio de Janeiro: Forense, 2009.

NEGRÃO, Ricardo. Manual de direito comercial e de empresa, vol. III, São Paulo: Saraiva, 2004.

OLIVEIRA, Celso Marcelo de. Manual de Direito Bancário. São Paulo: IOB Thomson, 2006.

OLIVEIRA, Marcos Cavalcante de. Moeda, Juros e Instituições Financeiras regime jurídico. Rio de Janeiro: Forense, 2006.

PAES, Paulo Roberto Tavares. Responsabilidade dos Administradores de Sociedades, $3^{\text {a }}$ ed., São Paulo: Atlas, 1999.

PAULIN, Luiz Alfredo. Conceito de intervenção e liquidação extrajudicial. In. SADDI, Jairo (org.). Intervenção e Liquidação Extrajudicial no Sistema Financeiro Nacional - 25 anos da Lei 6.024/74, São Paulo: Textonovo, 1999.

PEREIRA, Caio Mário da Silva. Responsabilidade civil. 9a ed. rev. e ampl. Rio de Janeiro: Forense, 1998.

PONTES DE MIRANDA, Francisco Cavalcanti. Tratado de direito privado. Rio de Janeiro: 
Borsoi, 1954. t. III, p. 231 e ss.

especial. Rio de Janeiro: Borsoi, 1961, t. XXX.

Tratado de direito privado - Parte

RAMOS, Saulo. Inexistência de responsabilidade do Governador do Estado pela gestão de banco estadual. Interpretação da Lei $n^{\circ}$ 6.024/74, in Revista de Direito Bancário e do Mercado de Capitais, São Paulo: RT, ano 1, nº1, p. 9-40, jan.-abr., 1998.

RÁO, Vicente. Liquidação extrajudicial - Responsabilidade solidária de diretores Requisitos legais para o sequestro de seus bens - Hipótese em que não deve ser decretada. Parecer. RT, São Paulo: RT, ano 45, nº 251, p. 48-56. set. 1956.

REQUIÃO, Rubens. Curso de direito falimentar. vol. II. 14a ed., São Paulo: Saraiva, 1995.

RODRIGUES, Frederico Viana. Insolvência bancária: liquidação extrajudicial e falência., Belo Horizonte: Mandamentos, 2004.

SADDI, Jairo (org.). Intervenção e Liquidação Extrajudicial no Sistema Financeiro Nacional - 25 anos da Lei 6.024/74, São Paulo: Textonovo, 1999.

. Intervenção e liquidação extrajudicial das instituições financeiras - recentes procedimentos adotados pelo Bacen e legalidade das medidas. In: MOSQUERA, Roberto Quiroga (Coord.). Aspectos atuais do direito do mercado financeiro e de capitais. São Paulo: Dialética, 1999.

; CAMARGO, Rodrigo Ferraz de (org.). Jurisprudência em Matéria de Intervenção e Liquidação Extrajudicial , vol. 1, São Paulo: Textonovo, 2000.

SALOMÃO NETO, Eduardo. Direito Bancário, São Paulo: Atlas, 2011.

SANTOS, Paulo Penalva (Coordenador). A Nova Lei de Falências e de Recuperação de Empresas - Lei 11.101/05. Rio de Janeiro: Forense, 2007.

SCARTEZZINI, Ana Maria Goffi Flaquer. A responsabilidade na liquidação extrajudicial da lei 6.024/74. Revista dos Tribunais, São Paulo: RT, vol. 10, p. 50-55, out.-dez. 2000.

SILVA, Alexandre Couto. Responsabilidade dos Administradores de S/A: business judment rule. Rio de Janeiro: Elsevier, 2007.

SILVA, Geraldo José Guimarães da. GUIMARÃES, Antônio Márcio da Cunha. Direito Bancário e Temas Afins. Campinas: CS, 2003.

SIMÃO FILHO, Adalberto; DE LUCCA, Newton (coordenadores). Comentários à nova lei de recuperação de empresas e de falências. São Paulo: Quartier Latin, 2005, p. 437.

SIMONI, Liane Maia. O regime jurídico da responsabilidade dos administradores de instituições financeiras. Revista de Direito Mercantil Industrial Econômico e Financeiro, São Paulo: 
RT, nº 44, Nova Série, p.28-69, out.-dez. 1981.

SIQUEIRA, Francisco J. de. Da responsabilidade civil dos administradores de instituições financeiras. Revista de Direito Mercantil, Industrial, Econômico e Financeiro, São Paulo: RT, nº 68, Nova Série, p. 31-49, out-dez. 1987.

. O papel do Banco Central no processo de intervenção e liquidação extrajudicial. In. SADDI, Jairo (org.). Intervenção e Liquidação Extrajudicial no Sistema Financeiro Nacional - 25 anos da Lei 6.024/74, São Paulo: Textonovo, 1999.

SKILES, John A. Individual Personal Liability of Banking Directors for Excessive Loans, Notre Dame Law Review, v. 7, issue 2.

STOCO, Rui. Tratado de Responsabilidade Civil, 8ª ed., São Paulo: RT, 2011.

TEPEDINO, Gustavo. A evolução da responsabilidade civil no direito brasileiro e suas controvérsias na atividade estatal. Temas de Direito Civil, Rio de Janeiro: Renovar, 1999.

TOLEDO, Paulo Fernando Campos Salles de. Liquidação extrajudicial de instituições financeiras: alguns aspectos polêmicos. Revista de Direito Mercantil, Industrial, Econômico e Financeiro, São Paulo: RT, nº 60, Nova Sério, p. 24-38, out.-dez. 1995, p. 24-38.

TOSETTI, Gian Maria. Intervenção nas instituições financeiras sob a égide da Lei 6.024/74. Revista de Direito Mercantil, Industrial, Econômico e Financeiro, São Paulo: RT, $n^{\circ} 41$, Nova Série, p. 74-91, jan.-mar. 1981.

TUCCI, Rogério Lauria. Ação civil pública: falta de legitimidade e interesse do Ministério Público. Revista dos Tribunais, São Paulo, Revista dos Tribunais, nº 745, nov. 1997.

TURCZYN, Sidnei. O Sistema Financeiro Nacional e a regulação bancária. São Paulo: RT, 2005.

TURCZYN, Sidnei. Indisponibilidade de bens dos administradores de instituições financeiras. Revista de Direito Público, São Paulo: RT, nº 47-48, p. 297-304, jul.-dez. 1978.

TZIRULNIK, Luiz. Intervenção e Liquidação Extrajudicial das Instituições Financeiras, $2^{\text {a }}$ ed., São Paulo: RT, 2000.

VALVERDE, Trajano de Miranda. Comentários à lei de falências. Rio de Janeiro: Revista Forense, 1999.

VENOSA, Ś́lvio de Salvo. Responsabilidade civil. Vol. 4. São Paulo: Atlas, 2003.

VERÇOSA, Haroldo Malheiros Duclerc. A reformulação da Lei 6.024, de 13.03.1974. Revista de Direito Mercantil, Industrial, Econômico e Financeiro, São Paulo: RT, nº 41, Nova Série, p. 29-39, jan.-mar. 1981.

A responsabilidade civil especial dos administradores e controladores de instituições financeiras, e a responsabilidade de outras 
pessoas a ela relacionadas, nos regimes extraordinários do direito brasileiro. 1990. Tese (Doutorado) sob a orientação do Prof. Fábio Konder Comparato - Faculdade de Direito, Universidade de São Paulo, São Paulo.

Bancos Centrais no Direito Comparado - O Sistema Financeiro Nacional e o Banco Central do Brasil, São Paulo: Malheiros, 2005.

Curso de Direito Comercial 3, São Paulo:

Malheiros, 2008.

Direito Comercial, $3^{\mathrm{a}}$ ed., São Paulo: RT, 2014.

Notas sobre a responsabilidade civil dos administradores e do controlador de instituições financeiras sob o Regime de Administração Especial Temporário - Raet. Revista de Direito Mercantil, Industrial, Econômico e Financeiro, São Paulo: RT, nº 104, Nova Série, p. 95-99, out.-dez. 1996.

Responsabilidade civil especial nas instituições financeiras e nos consórcios em liquidação extrajudicial, São Paulo: RT, 1993.

. A responsabilidade civil especial nas instituições financeiras insolventes. In. SADDI, Jairo (org.). Intervenção e Liquidação Extrajudicial no Sistema Financeiro Nacional - 25 anos da Lei 6.024/74, São Paulo: Textonovo, 1999.

WAISBERG, Ivo. Responsabilidade Civil dos Administradores de Bancos Comerciais: regimes especiais: intervenção, liquidação extrajudicial, regime de administração especial temporária - RAET. São Paulo: RT, 2002.

WALD, Arnoldo; WALD, Alexandre. O descabimento da indisponibilidade dos bens dos exadministradores de instituição financeira em liquidação extrajudicial, quando o inquérito realizado pelo Banco Central não apura nexo causal entre a conduta e o prejuízo. In. SADDI, Jairo (org.). Intervenção e Liquidação Extrajudicial no Sistema Financeiro Nacional 25 anos da Lei 6.024/74, São Paulo: Textonovo, 1999.

WALD, Arnoldo. A culpa e o risco como fundamento da responsabilidade pessoal do diretor do Banco. Revista de Direito Mercantil Industrial Econômico e Financeiro, São Paulo: RT, $\mathrm{n}^{\mathrm{o}}$ 24, Nova Série, p. 29-43, 1976.

. O arresto e a indisponibilidade na Lei 6.024/74, Revista de Direito Mercantil, Industrial, Econômico e Financeiro, São Paulo: RT, nº 33, Nova Série, p. 11-23, jan.-mar. 1979.

YAZBEK, Otavio. Regulação do Mercado Financeiro e de Capitais. $2^{\mathrm{a}}$ ed. Rio de Janeiro: Elsevier, 2009. 


\section{Enderecos eletrônicos consultados}

$<$ http://oglobo.globo.com/economia/na-uniao-europeia-10-milhoes-estaodesempregados- hamais-de-um-ano-9603458>. Consultado em 4.6.2016.

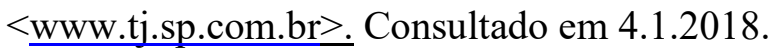

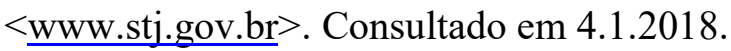

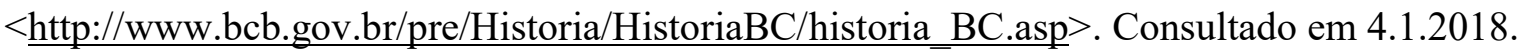

$<$ https://www.bcb.gov.br/htms/public/BancosEstaduais/livros_bancos_oficiais.pdf $>$.

Consultado em 4.1.2018.

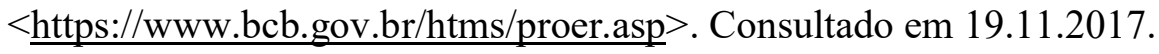

$<$ https://www3.bcb.gov.br/audpub/DetalharAudienciaPage?4 $>$. Consultado em 4.1.2018.

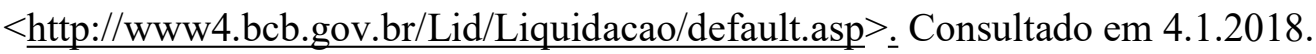

http://www.bcb.gov.br/pec/appron/apres/Semin\%E1rio\%20de $\% 20$ Resolu $\%$ E7\%E3o\%20de< $\% 20 \mathrm{Fal} \% \mathrm{EAncia} \% 20 \mathrm{de} \% 20$ Institui $\% \mathrm{E} 7 \% \mathrm{~F} 5 \mathrm{es} \% 20 \mathrm{Financeiras} \% 20271009$.pdf $>$. Consultado em 4.1.2018.

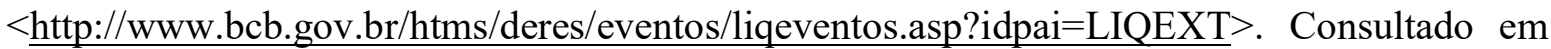
4.1.2018.

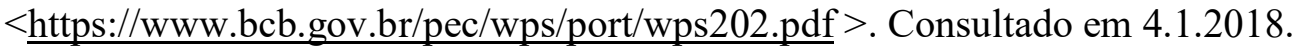

$<$ http://www2.camara.leg.br/atividade-legislativa/comissoes/comissoestemporarias/parlamentar-deinquerito/51-legislatura/cpiproer/relatoriofinal.html $>$. Consultado em 4.1.2018.

$<$ https://www25.senado.leg.br/web/atividade/materias/-/materia/113458 $>$. Consultado em 22.11 .2017$.

$<$ https://www.fdic.gov/bank/individual/failed/banklist.html $>$ Consultado em 1.7.2016

$<$ http://www.fdic.gov/regulations/laws/rules/5000-3300.html\#fdic5000statementct $>$ Consultado em 1.7.2016

$<$ https://www.fdic.gov/about/strategic/strategic/mission.html $>$ Consultado em 1.7.2016.

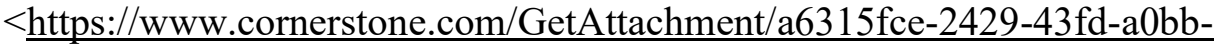
aedd86f72e71/Characteristics-of-FDIC-Lawsuits-Sep-2013.pdf $>$. Consultado em 1.7.2016. 


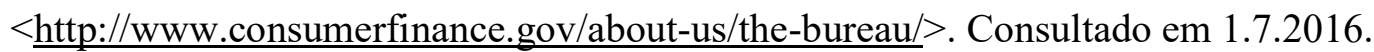

$<$ http://professorsimao.com.br/artigos simao a teoria do risco.htm $>$. Consultado

em 4.1.2018.

$<$ https://www.investopedia.com/terms/t/too-big-to-

fail.asp; https://www.ft.com/content/0bd8f4d4-76de-11e7-a3e8-60495fe6ca71>. Consultado em 4.1.2018. 